\title{
Synthesis and Thermal Properties of Polyamide 6-block-Poly(cyclohexylmaleimide)
}

\author{
Tetsuji Hirano, ${ }^{*}$ Kenjiro Onimura, Hiromori Tsutsumi, and Tsutomu Oishi ${ }^{\dagger}$ \\ Faculty of Engineering, Yamaguchi University, 2557 Tokiwadai, Ube, \\ Yamaguchi 755-8611, Japan \\ * Polymer Laboratory, Ube Industries, Ltd., 1-12-32 Nishihonmachi, Ube, \\ Yamaguchi 755-8633, Japan \\ (Received September 16, 1998)
}

\begin{abstract}
Block copolymers consisting of poly(cyclohexylmaleimide) (PCHMI) and polyamide 6 (PA6) were synthesized and thermal properties were measured. Carboxyl group-terminated PCHMIs initiated by 4,4'-azobis-4-cyanopentanonic acid (ACPA) under several conditions had different $T_{\mathrm{g}} \mathrm{s}$, depending on the molecular weight of PCHMI. Copolymers consisting of PA6 and PCHMI were prepared by melt-polymerization of $\varepsilon$-caprolactam, 6-aminocapronic acid and PCHMI. The copolymers contained $\mathrm{ABA}$ and $\mathrm{AB}$ judging from ${ }^{1} \mathrm{H}$ NMR and reduced viscosity measurements. $T_{\mathrm{g}} \mathrm{s}$ of the copolymers were independent of $T_{\mathrm{g}}$ of the original PCHMI, and increased with PCHMI content in the copolymers.

KEY WORDS Polyamide 6/Poly(cyclohexylmaleimide) / Block Copolymer / Melt-Polymerization / Thermal Properties /
\end{abstract}

Polyamide 6 (PA6) has many industrial applications, and block copolymers from PA6 and other polymers, such as vinyl polymers, polyethers, polyimides, and polyesters, were synthesized to expect new properties. ${ }^{1}$ However, major vinyl polymers copolymerized with PA6 are poly(styrene $)^{2-7}$ and rubbers such as poly(butadiene-acrylonitrile), ${ }^{8-11}$ poly(styrenebutadiene), ${ }^{12,13}$ poly(butadiene) ${ }^{6,14-16}$ and poly(isobutylene) ${ }^{17}$ There have been few studies on the synthesis and characterization of block copolymers of PA6 with vinyl polymers, except poly(styrene) and rubbers.

The polymerization of $\varepsilon$-caprolactam $(\mathrm{CL})$ has been initiated with end groups of prepolymers consisting of other polymers for prepolymers having amino or carboxyl end groups. ${ }^{1}$ In the preparation of block copolymers, initiators such as dicarboxylic acids, $\omega$ aminocarboxylic acids, or water were often added to the system to increase the rate of copolymerization. ${ }^{1}$ In general, however, the preparations were carried out above the melting points $\left(T_{\mathrm{m}}\right)$ of copolymers. ${ }^{1}$ Thus, thermal stability of the prepolymers is required.

Poly( $N$-substituted maleimide)s (poly(RMI)s) have usually good thermal stability and various properties depending on the $N$-substituents. ${ }^{18}$ Since homopolymers are brittle, copolymers with other vinyl monomers were usually used. The unique thermal and optical properties, and characteristic of separation of the copolymers have been reported. ${ }^{18}$

Poly $(N$-cyclohexylmaleimide) (PCHMI) has a high softening point ${ }^{19}$ and thermal decomposition temperature. ${ }^{20}$ Block copolymers from PA6 and PCHMI are of great interest from the point of synthesis and thermal properties. The present paper describes the synthesis of PA6-block-PCHMI from CL, 6-aminocapronic acid (ACA) and carboxyl group-terminated PCHMI obtained from the radical polymerization of CHMI with 4,4'azobis-4-cyanopentanonic acid (ACPA). Thermal properties of the copolymers were investigated by differential scanning calorimetry (DSC) and dynamic mechan- ical spectrometry.

\section{EXPERIMENTAL}

\section{Materials}

CL (Ube Ind., Ltd.) was commercial-grade. CHMI (melting point; $89^{\circ} \mathrm{C}$ ) was prepared as described earlier. ${ }^{19}$ ACA, $m$-cresol, methanol, tetrahydrofuran (THF), 1,4dioxane (DOX) and 1-methyl-2-pyrrolidinone (NMP) as extra pure grades of Kishida Chemical Co. were used without further purification. ACPA (Aldrich) was recrystallized twice from methanol.

\section{Polymerization}

Carboxyl-Terminated PCHMI. The radical polymerizations of CHMI with ACPA as the initiator were carried out in THF or DOX at $60^{\circ} \mathrm{C}$ under nitrogen atmosphere. After a required time, the solution was cooled to r.t. and filtered to remove insoluble parts. PCHMI was precipitated by pouring the filtrate into excess of methanol-water ( $=85: 15$, weight) mixture, filtered, washed 3 times, and dried under reduced pressure at r.t. for 1 day.

PA6-block-PCHMI and PA6 Homopolymer. The copolymers were prepared by melt-polymerizations under nitrogen atmosphere. PCHMI was dissolved in CL and $\mathrm{ACA}$ at $180^{\circ} \mathrm{C}$ for $30 \mathrm{~min}$. The mixture solution was heated at $250^{\circ} \mathrm{C}$ for the desired time. The products were crushed and washed with methanol and THF by Soxhlet apparatus for $5 \mathrm{~h}$ to remove the monomers, oligomers and unreacted PCHMI. The products were dried under reduced pressure at $r$.t. for 1 day.

PA6 homopolymer was obtained by the hydrolytic polymerization of $\mathrm{CL}$ in the presence of stearylamine (SA) as terminator. CL, water and SA were heated in a stainless steel reactor under nitrogen atmosphere at $250^{\circ} \mathrm{C}$. PA6 was washed with methanol by Soxhlet apparatus for $20 \mathrm{~h}$ and dried under reduced pressure at $60^{\circ} \mathrm{C}$ for 1 day.

\footnotetext{
† To whom all correspondence should be addressed.
} 


\section{Characterization}

${ }^{1} H$ NMR Spectroscopy. PCHMI was dissolved in $\mathrm{CDCl}_{3}$. PA6 and PA6-block-PCHMI were dissolved in $\mathrm{D}_{2} \mathrm{SO}_{4}(97 \%) .{ }^{1} \mathrm{H}$ NMR spectra were measured using a JEOL JNM-EX400WB FT-NMR (400 MHz) spectrometer at r.t. Tetramethylsilane (TMS) was used as the internal standard.

End Group. The concentrations of carboxyl groups in PCHMI were measured by potentiometric titration in NMP at r.t. with $0.1 \mathrm{~N}$ sodium methoxide in pyridine. The concentrations of amino groups in PA6 were measured by titration in phenol/methanol $\left(90 / 10_{\text {volume }}\right)$ at r.t. with $0.05 \mathrm{~N}$ sodium hydroxide.

Molecular Weight. Number-average $\left(M_{n}\right)$ and weightaverage $\left(M_{w}\right)$ molecular weights of PCHMI were measured by GPC using a Shimadzu Chromatopac C-E4A, SPD-10A UV detector and LC-10A pump with columns of HSG- $10 \mathrm{H}, 15 \mathrm{H}, 20 \mathrm{H}$, and $40 \mathrm{H}$. THF was used as solvent; column temperature $=50^{\circ} \mathrm{C}$, and flow rate $=0.8$ $\mathrm{ml} \mathrm{min}{ }^{-1}$. $M_{n}$ and $M_{w}$ were calibrated with a polystyrene standard.

$M_{n}$ of PCHMI were measured by vapor pressure osmometry (VPO), performed using a CORONA Molecular Weight Apparatus 114 at $30^{\circ} \mathrm{C}$. THF was used as solvent.

$M_{n}$ of PA6 was calculated from concentrations of amino groups.

Solution Viscosity. Reduced viscosity $\left(\eta_{\mathrm{red}}\right)$ of $0.5 \mathrm{~g} \mathrm{dl}^{-1}$ PCHMI and PA6-block-PCHMI solution in $m$-cresol were measured using an Ostwald viscometer at $25^{\circ} \mathrm{C}$.

Thermal Properties. DSC was used for thermal measurement with a Perkin-Elmer Model DSC-7. PCHMI was first heated to $320^{\circ} \mathrm{C}$, cooled to $0^{\circ} \mathrm{C}$, and scanned at $10^{\circ} \mathrm{C} \mathrm{min}^{-1}$. Copolymers were first heated to $260^{\circ} \mathrm{C}$, cooled to $-40^{\circ} \mathrm{C}$ at $10^{\circ} \mathrm{C} \mathrm{min}^{-1}$ and scanned at $10^{\circ} \mathrm{C}$ $\min ^{-1}$.

Dynamic mechanical spectrometry was performed using a Rheometrics RSA II at $10 \mathrm{~Hz}$. The specimen was prepared from $m$-cresol solution $(15 \mathrm{wt} \%)$ poured on to a glass plate and the solvent was evaporated at $70^{\circ} \mathrm{C}$ for $24 \mathrm{~h}$. The film (about $25 \mu \mathrm{m}$ in thickness) was washed with methanol by Soxhlet apparatus for $5 \mathrm{~h}$ to remove remaining solvent and dried under reduced pressure at r.t. for 1 day.

\section{RESULTS AND DISCUSSION}

\section{Synthesis of Carboxyl Group-Terminated PCHMI}

According to Scheme 1, carboxyl group-terminated PCHMI was synthesized by radical polymerization of CHMI with ACPA. Figure 1 shows ${ }^{1} \mathrm{H}$ NMR spectra of PCHMI. Assignments of signals based on CHMI unit are presented elsewhere. ${ }^{21}$ Signals of methyl protons (A) coalesced with those of methylene protons of cyclohexyl groups (a) which appeared at the same range $(0.9-2.2 \mathrm{ppm})$. The intensity of signals at $2.60-2.95$ ppm increased with decrease of the molecular weight and thus were assigned to two methylene protons of ACPA unit (B) in PCHMI.

The results of the synthesis of PCHMI are summarized in Table I. Polymerization with ACPA proceeded first

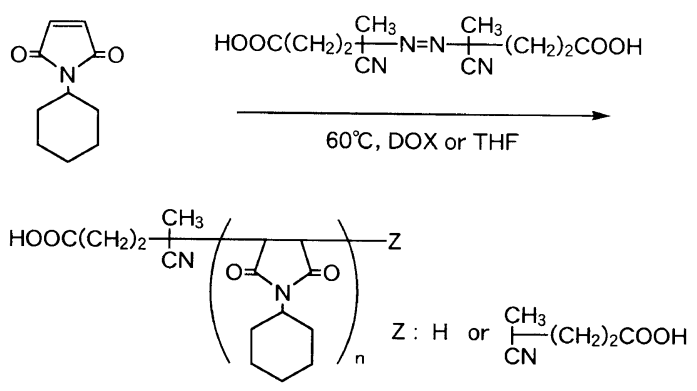

Scheme 1. Synthesis of carboxyl group-terminated PCHMI.

(a)

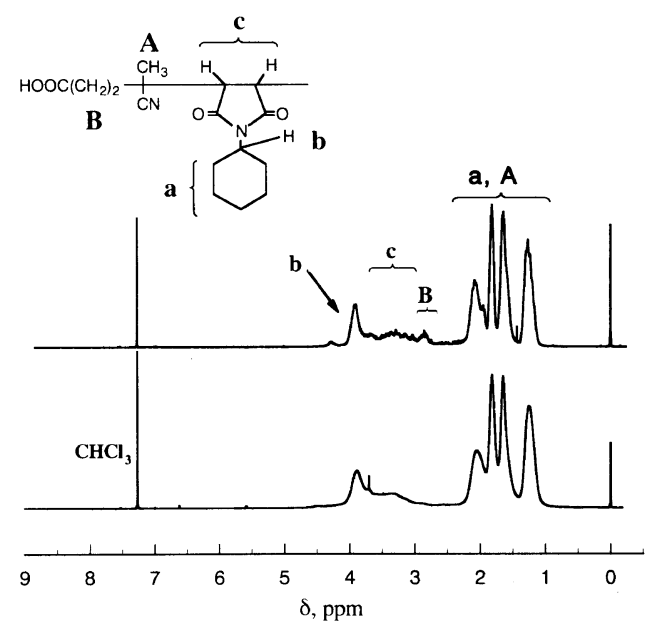

Figure 1. ${ }^{1} \mathrm{H}$ NMR spectra of $\mathrm{PCHMI}$ in $\mathrm{CDCl}_{3}$ : (a) Run $\mathrm{T} 6$ and (b) Run D7 (in Table I).

homogeneously in THF and DOX and heterogeneously as well as that of CHMI with $2,2^{\prime}$-azobis(isobutyronitrile) (AIBN) in THF. ${ }^{19}$ In this study, only the dissolved component in the solvent was used. $M_{n}$ and $M_{w}$ of PCHMI, except at lower concentration of ACPA (Run D1 and T1), slightly decreased with increasing molar ratio of ACPA to CHMI. $M_{n}$ and $M_{w}$ of PCHMI obtained in DOX were higher than in THF.

Otsu et al. reported that the polymerization of styrene with ACPA gave telekelic polymers with carboxyl groups at chain-ends, but the telekelic polymer was not obtained for the polymerization of methyl acrylate. ${ }^{22}$ As shown in Table I, the number of carboxyl groups per polymer chain $\left(N_{\mathrm{c}}\right)$ calculated from the concentration of carboxyl group and $M_{n}$ measured by GPC, except for D1, were smaller than 2.0. $M_{n}$ of D1, D3, and T2 measured by VPO $\left(M_{n_{\mathrm{VPO}}}\right)$ were $3.1 \times 10^{3}, 1.4 \times 10^{3}$, and $1.0 \times 10^{3}$, respectively. These values were similar to those by GPC, and $N_{\mathrm{c}}$ calculated from the $M_{n_{\mathrm{VPO}}}$ were smaller then 2.0. This suggests that the radical polymerization of CHMI with ACPA is not terminated only by the recombination reaction. Thus, copolymerization using PCHMI is expected to form copolymers having $\mathrm{ABA}$ and $\mathrm{AB}$ structures (A, PA6 segment; B, PCHMI).

Figure 2 shows DSC curves of PCHMI. Melting was not observed. The glass transition temperature $\left(T_{\mathrm{g}}\right)$ increased with $M_{n}$, as shown in Figure 3. In general, $M_{n}$ dependence on $T_{\mathrm{g}}$ is expressed by Fox and Flory ${ }^{23}$ as,

$$
T_{\mathrm{g}}=T_{\mathrm{g} \infty}-\frac{K}{M_{n}}
$$


Table I. Radical polymerization of CHMI with ACPA at $60^{\circ} \mathrm{C}$

\begin{tabular}{|c|c|c|c|c|c|c|c|c|c|c|}
\hline \multirow{3}{*}{ Run } & \multirow{3}{*}{ Solvent ${ }^{\mathrm{a}}$} & \multicolumn{2}{|c|}{ Feed } & \multirow{3}{*}{$\frac{\text { Time }}{\mathrm{h}}$} & \multirow{3}{*}{$\frac{\text { Yield }}{\%}$} & \multirow{3}{*}{$\frac{M_{n}^{\mathrm{b}}}{\times 10^{-3}}$} & \multirow{3}{*}{$\frac{M_{w}{ }^{\mathrm{b}}}{\times 10^{-3}}$} & \multirow{3}{*}{$\frac{[\mathrm{COOH}]^{\mathrm{c}}}{\mathrm{mmol} \mathrm{g}^{-1}}$} & \multirow{3}{*}{$N_{\mathrm{C}}^{\mathrm{d}}$} & \multirow{3}{*}{$\frac{T_{\mathrm{g}}{ }^{\mathrm{e}}}{{ }^{\circ} \mathrm{C}}$} \\
\hline & & [CHMI] & [ACPA $]$ & & & & & & & \\
\hline & & $\mathrm{mol} \mathrm{L}^{-1}$ & $\times 10^{2} / \mathrm{mol} \mathrm{L}^{-1}$ & & & & & & & \\
\hline D1 & DOX & 0.46 & 0.12 & 24 & 54.6 & 3.7 & 7.0 & 0.58 & 2.1 & 276 \\
\hline D2 & DOX & 0.46 & 0.46 & 16 & 83.1 & 2.0 & 4.4 & & & 252 \\
\hline D3 & DOX & 0.42 & 2.10 & 16 & 82.5 & 1.7 & 3.9 & 0.94 & 1.6 & 247 \\
\hline D4 & DOX & 0.42 & 4.20 & 16 & 82.3 & 1.7 & 3.9 & & & 243 \\
\hline D5 & DOX & 0.42 & 8.40 & 16 & 78.8 & 1.5 & 3.3 & & & 235 \\
\hline D6 & DOX & 0.42 & 16.80 & 16 & 74.4 & 1.2 & 2.9 & & & 223 \\
\hline D7 & DOX & 0.28 & 11.20 & 16 & 72.3 & 1.5 & 3.0 & 1.01 & 1.5 & 232 \\
\hline $\mathrm{T} 1$ & THF & 0.46 & 0.05 & 24 & 37.3 & 3.9 & 7.8 & 0.36 & 1.4 & 272 \\
\hline $\mathrm{T} 2$ & THF & 0.46 & 0.46 & 16 & 88.1 & 0.7 & 1.0 & 1.53 & 1.1 & 113 \\
\hline $\mathrm{T} 3$ & THF & 0.28 & 0.56 & 16 & 58.1 & 1.3 & 2.5 & & & 193 \\
\hline $\mathrm{T} 4$ & THF & 0.28 & 0.70 & 16 & 75.4 & 0.7 & 1.0 & 2.48 & 1.7 & 135 \\
\hline T5 & THF & 0.28 & 2.80 & 16 & 59.2 & 0.6 & 0.7 & & & 118 \\
\hline T6 & THF & 0.28 & 5.60 & 16 & 72.8 & 0.7 & 0.9 & & & 126 \\
\hline
\end{tabular}

${ }^{a}$ DOX, 1,4-dioxane; THF, tetrahydrofuran. ${ }^{\mathrm{b}}$ Measured by GPC based on standard polystyrene. ${ }^{\mathrm{c}}$ Measured by titration. ${ }^{\mathrm{d}} \mathrm{Number}$ of $\mathrm{COOH}$ per PCHMI chain calculated from $[\mathrm{COOH}]$ and $M_{n} \cdot{ }^{\mathrm{e}}$ Measured by DSC, rate $=10^{\circ} \mathrm{Cmin}^{-1}$.

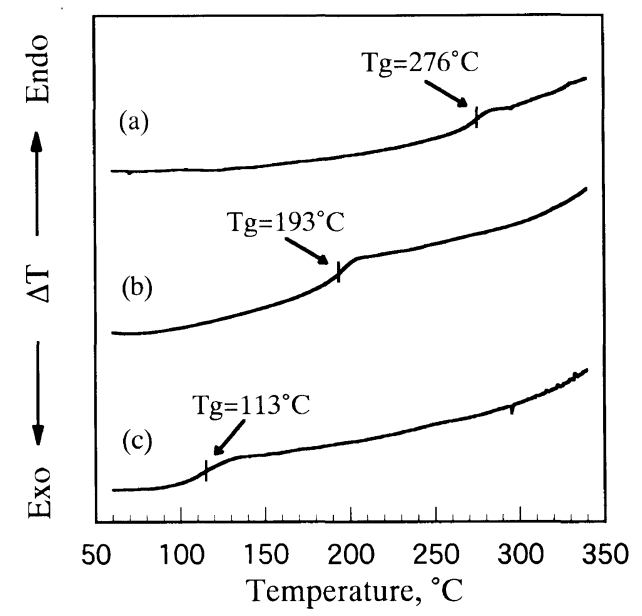

Figure 2. DSC curves of PCHMI having different molecular weight: (a) Run D1 $\left(M_{n}=3700\right)$, (b) Run T3 $\left(M_{n}=1300\right)$ and (c) Run T2 $\left(M_{n}=700\right)$.

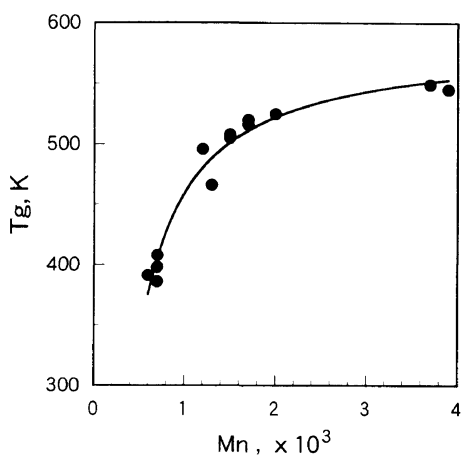

Figure 3. Effects of $M_{n}$ on $T_{\mathrm{g}}$ of PCHMI; experimental data (-) and carve fitting (-) with eq: $T_{\mathrm{g}}=T_{\mathrm{g} \infty}-K / M_{n} \quad\left(T_{\mathrm{g} \infty}=586 \mathrm{~K}\right.$; and $\left.K=1.26 \times 10^{5}\right) . \quad M_{n}$ was measured by GPC based on standard polystyrene, and $T_{\mathrm{g}}$ by DSC $\left(10^{\circ} \mathrm{C} \mathrm{min}^{-1}\right)$.

where $T_{\mathrm{g} \infty}$ is the limiting $T_{\mathrm{g}}$ at high molecular weight and $K$ is a polymer specific constant. Fit of eq 1 was in fair agreement with the experimental data. $T_{\mathrm{g} \infty}$ and $K$ were $586 \mathrm{~K}\left(313^{\circ} \mathrm{C}\right)$ and $1.26 \times 10^{5}$, respectively.
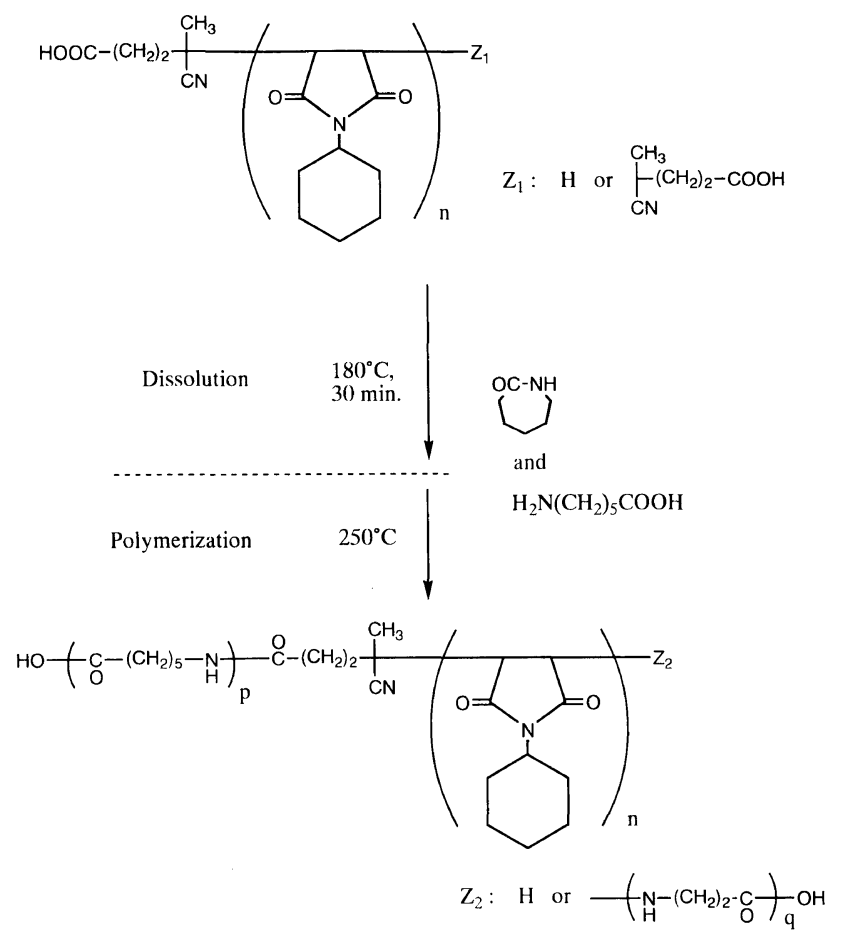

Scheme 2. Synthesis of PA6-block-PCHMI.

Syntheses of PA 6-block-PCHMI

Several block copolymers have been prepared by the hydrolytic polymerization of CL with carboxyl groupterminated prepolymers. ${ }^{1}$ In this study, it was presumed that imide rings of PCHMI are hydrolyzed as well as CL. Yumoto et al. $^{24}$ and Kruissink et al. $^{25}$ reported the polymerization of CL to be initiated with ACA in the absence of water. To avoid hydrolysis of imide rings, PA6-block-PCHMI were prepared using ACA, as shown in Scheme 2. PCHMI was dissolved in molten CL and thus copolymers were synthesized by the dissolution of PCHMI in molten CL at $180^{\circ} \mathrm{C}$ for $30 \mathrm{~min}$, followed by heating at $250^{\circ} \mathrm{C}$ for a desired time. When PCHMI was dissolved in basic solvents such as $N, N$-dimethylformamide and dimethylsufoxide, the solution turned red. ${ }^{19}$ 
The same was observed when PCHMI was dissolved in molten CL. When the reaction was complete, the solution and product turned brown. The ${ }^{1} \mathrm{H}$ NMR spectrum of PA6-block-PCHMI is shown in Figure 4. Some signals based on PA6 and PCHMI were observed.

The polymerization of CL and ACA on addition of $4 \mathrm{wt} \%$ PCHMI (T1 in Table I) is summarized in Table II. Solution viscosity increased with reaction time, and became approximately constant after $4 \mathrm{~h}$. As shown in Figure 5, the intensity of the signal $(F)$ at $2.69 \mathrm{ppm}$, assigned to methylene protons of PA6 segments adjacent to amino groups, decreased with reaction time, compared with that (E) of methylene protons of PA6 segments adjacent to carboxyl groups. Hallden-Abberton reported

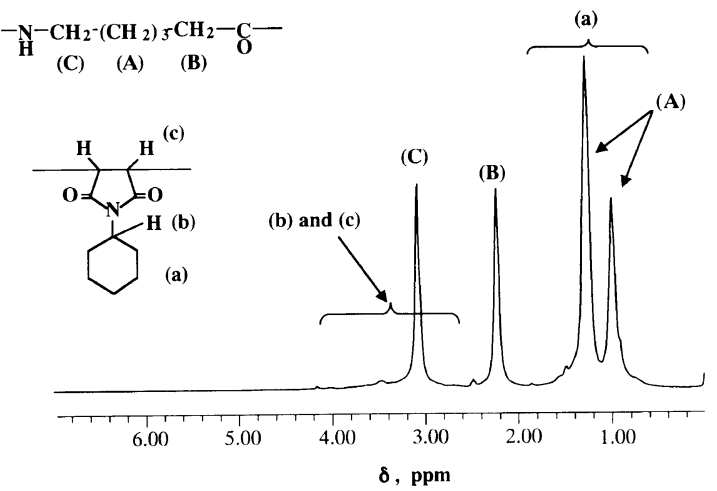

Figure 4. ${ }^{1} \mathrm{H}$ NMR spectrum of PA 6-block-PCHMI (Run CP14) in $\mathrm{D}_{2} \mathrm{SO}_{4}$. no grafting when polyamide and polyglutarimide, which has little acid and/or anhydride sites, are mixed at $275^{\circ} \mathrm{C}$ in an extruder. ${ }^{26}$ This suggests that no reaction between amino groups of polyamide and imide groups of polyglutarimide occurs. Reaction between amino groups of PA6 and imide groups of PCHMI prevents the polymerization of PA6 segments, but the average number of repeating units for PA6 segments increases with reaction times. It is presumed, therefore, that reaction between amino groups of PA6 and imide rings little occurs as well as results of Hallden-Abberton's study. The decrease of amino groups of PA6 segments may be caused by reaction via carboxyl end groups of PCHMI. Since PA6 segments connecting PCHMI have no amino groups and all PA6 segments have carboxyl end groups, the molar fraction of PA6 segments not bonded to PCHMI, $R_{0}$, may be calculated as,

$$
R_{0}=\frac{\left[\mathrm{NH}_{2}\right]_{\mathrm{PA} 6}}{[\mathrm{COOH}]_{\mathrm{PA} 6}}=\frac{S_{\mathrm{F}}}{S_{\mathrm{E}}}
$$

where $\left[\mathrm{NH}_{2}\right]_{\text {PA6 }}$ and $[\mathrm{COOH}]_{\text {PA6 }}$ are concentrations of amino and carboxyl end groups of PA6 segments, $S_{\mathrm{E}}$ and $S_{\mathrm{F}}$ are intensity of the signal (E) and signal (F). $R_{0}$ decreased with reaction time and $R_{0}$ for the copolymer CP5 in Table II could not be determined. More than $90 \%$ of PA6 segments may thus be bonded to PCHMI after $4 \mathrm{~h}$ at $250^{\circ} \mathrm{C}$ because $R_{0}$ was below 0.1 in this measurement.

The average number of repeating units for PA6 seg-

Table II. Copolymerization of $\mathrm{CL}$ and ACA with PCHMI

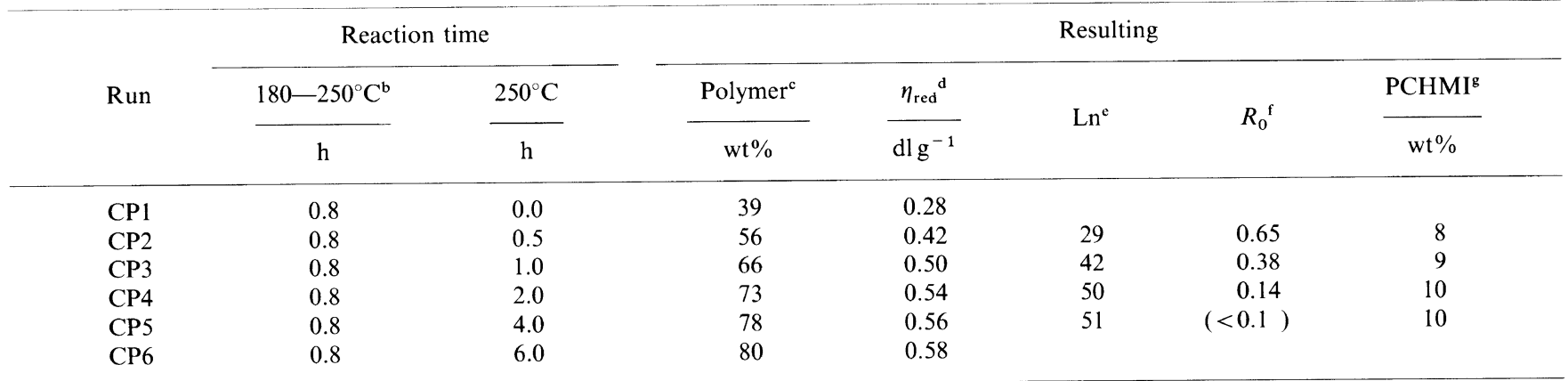

${ }^{\mathrm{a}} \mathrm{CL} / \mathrm{ACA} / \mathrm{PCHMI}(\mathrm{Tl})=(0.85 / 0.11 / 0.04)_{\text {weight }}{ }^{\mathrm{b}}$ Heated at $180^{\circ} \mathrm{C}$ for $30 \mathrm{~min}$ and raised to $250^{\circ} \mathrm{C}$ for about $20 \mathrm{~min}$. ${ }^{\mathrm{c}}$ Insoluble part in methanol and THF. ${ }^{\mathrm{d}}$ Measured in $m$-cresol at $25^{\circ} \mathrm{C}, c=0.5 \mathrm{~g} \mathrm{dl}^{-1}$. ${ }^{\mathrm{e}}$ Average number of repeating units for Nylon 6 block; calculated from ${ }^{1} \mathrm{H}$ NMR data. ${ }^{\mathrm{f}}$ Molar fraction of PA6 segments which was not bonded to PCHMI. ${ }^{\mathrm{g}}$ Calculated from ${ }^{1} \mathrm{H}$ NMR data.

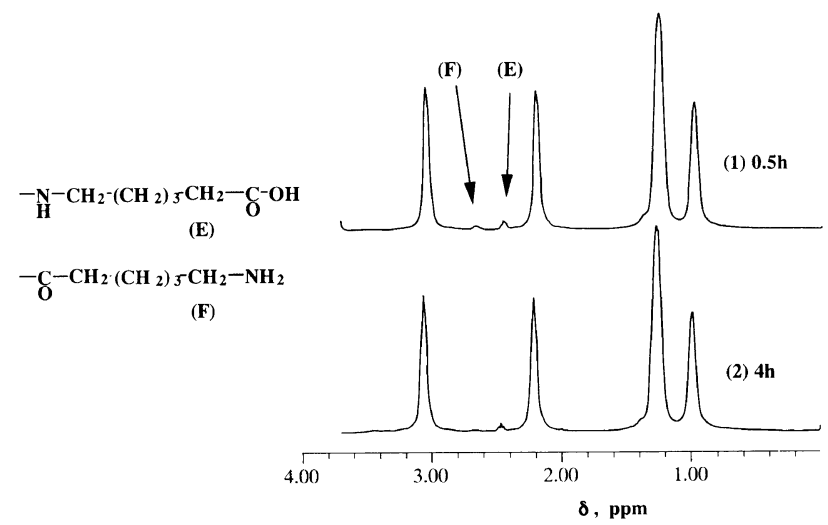

Figure 5. ${ }^{1} \mathrm{H}$ NMR spectra of Nylon 6-block-PCHMI in $\mathrm{D}_{2} \mathrm{SO}_{4}$ : (1) Run CP2 $\left(250^{\circ} \mathrm{C} \times 0.5 \mathrm{~h}\right) ;(2)$ Run CP5 $\left(250^{\circ} \mathrm{C} \times 4 \mathrm{~h}\right)$.

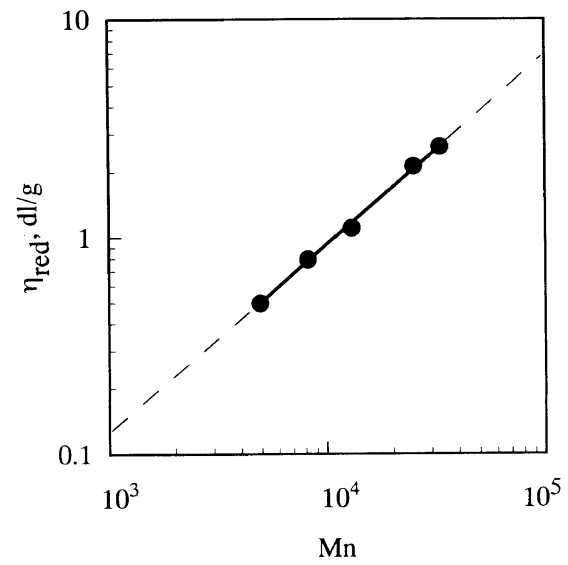

Figure 6. Relationship between $\eta_{\text {red }}$ and $M_{n}$ of PA6 homopolymer. $\eta_{\text {red }}$ was measured in $m$-cresol at $25^{\circ} \mathrm{C}, c=0.5 \mathrm{~g} \mathrm{dl}^{-1} . M_{n}$ was calculated from end group concentration. 
T. Hirano et al.

Table III. Syntheses of PA6 -block- PCHMI and their thermal properties

\begin{tabular}{|c|c|c|c|c|c|c|c|c|}
\hline \multirow{3}{*}{ Run } & \multirow{2}{*}{\multicolumn{2}{|c|}{$\begin{array}{c}\text { Feed }^{\mathrm{a}} \\
\text { PCHMI }^{\mathrm{c}}\end{array}$}} & \multicolumn{3}{|c|}{ Copolymers } & \multicolumn{3}{|c|}{ Thermal properties } \\
\hline & & & \multirow{2}{*}{$\frac{\mathrm{PCHMI}^{\mathrm{d}}}{\mathrm{wt} \%}$} & \multirow{2}{*}{$\frac{\eta_{\text {red }}^{\mathrm{e}}}{\mathrm{dlg}^{-1}}$} & \multirow{2}{*}{$\operatorname{Ln}^{\mathrm{f}}$} & \multirow{2}{*}{$\frac{T_{\mathrm{gRSA}}{ }^{\mathrm{g}}}{{ }^{\circ} \mathrm{C}}$} & \multirow{2}{*}{$\frac{T_{\mathrm{gDSC}}{ }^{\mathrm{h}}}{{ }^{\circ} \mathrm{C}}$} & \multirow{2}{*}{$\frac{T_{m}{ }^{\mathrm{h}}}{{ }^{\circ} \mathrm{C}}$} \\
\hline & Run No. & wt $\%$ & & & & & & \\
\hline $\mathrm{PA}^{\mathrm{b}}$ & & & & & & 79 & 42 & 221 \\
\hline CP11 & $\mathrm{T} 1$ & 15 & 14 & 0.38 & 44 & & 61 & 214 \\
\hline CP12 & $\mathrm{T} 1$ & 9 & 12 & 0.48 & 51 & & 57 & 216 \\
\hline CP13 & $\mathrm{T} 1$ & 5 & 7 & 0.60 & 68 & 98 & 55 & 218 \\
\hline CP14 & $\mathrm{T} 3$ & 10 & 16 & 0.43 & 46 & & 63 & 216 \\
\hline CP15 & $\mathrm{T} 3$ & 5 & 9 & 0.60 & 62 & & 53 & 219 \\
\hline CP16 & T6 & 5 & 7 & 0.72 & 66 & 94 & 52 & 220 \\
\hline CP17 & D7 & 10 & 9 & 0.48 & 58 & 94 & 56 & 218 \\
\hline CP18 & D7 & 5 & 7 & 0.60 & 75 & 91 & 55 & 220 \\
\hline
\end{tabular}

${ }^{\text {a }}$ Polymerization at $250^{\circ} \mathrm{C}$ for $5 \mathrm{~h}^{\mathrm{b}}{ }^{\mathrm{b}} \mathrm{M}_{\mathrm{n}}=1.3 \times 10^{4}$. ${ }^{\mathrm{c}}$ See Table I, $T_{\mathrm{g}}=\mathrm{T} 1\left(272^{\circ} \mathrm{C}\right), \mathrm{T} 3\left(193^{\circ} \mathrm{C}\right), \mathrm{T} 6\left(126^{\circ} \mathrm{C}\right)$, and D7(232 $\left.{ }^{\circ} \mathrm{C}\right)$. ${ }^{\mathrm{d}} \mathrm{Calculated}$ from ${ }^{1} \mathrm{H}$ NMR data. ${ }^{\mathrm{e}}$ Measured in $m$-cresol at $25^{\circ} \mathrm{C}, c=0.5 \mathrm{~g} \mathrm{dl}^{-1}$. ${ }^{\mathrm{f}}$ Average number of repeating units for PA6 segments; calculated from ${ }^{1} \mathrm{H}$ NMR data. ${ }^{\mathrm{g}}$ Measured by a dynamic mechanical spectrometer, temperature of maximum $E^{\prime \prime}$. ${ }^{\mathrm{h}} \mathrm{Measured} \mathrm{by} \mathrm{DSC}$, rate $10^{\circ} \mathrm{C}$ min ${ }^{-1}$.

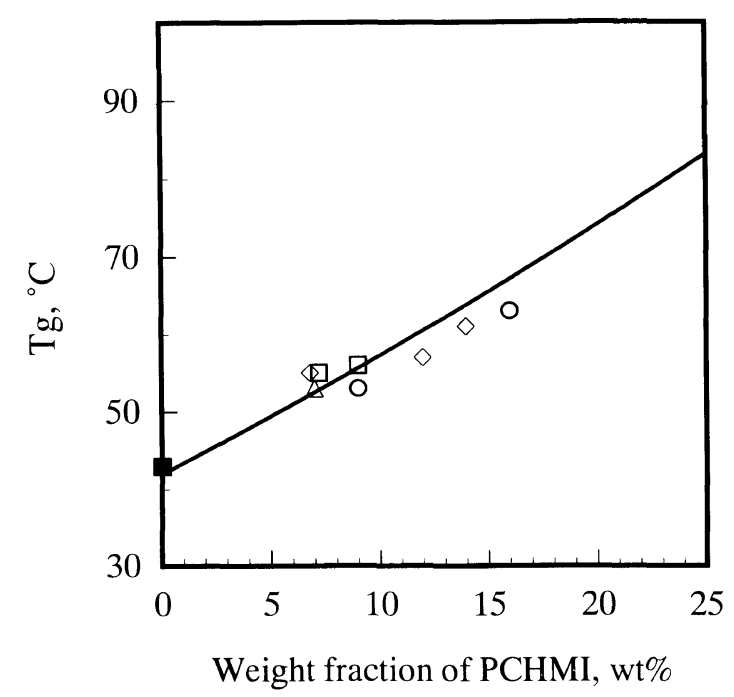

Figure 7. Effects of PCHMI content on $T_{\mathrm{g}}$ of PA6-block-PCHMI obtained from Run T1 $\left(T_{\mathrm{g}}=272^{\circ} \mathrm{C}\right)(\diamond)$, Run T3 $\left(T_{\mathrm{g}}=193^{\circ} \mathrm{C}\right)(\mathrm{O})$, Run T6 $\left(T_{\mathrm{g}}=126^{\circ} \mathrm{C}\right)(\triangle)$, and Run D7 $\left(T_{\mathrm{g}}=232^{\circ} \mathrm{C}\right)(\square)$ : PA6 homopolymer $\left(M_{n}=1.3 \times 10^{4} ; T_{\mathrm{g}}=43^{\circ} \mathrm{C}\right)(\square)$ and calculated data (-) by Fox equation.

ments, Ln, of the copolymer obtained for $4 \mathrm{~h}$ was 51 (CP5 in Table II). This indicates that a chain of the copolymer has 102 units of ACA corresponding to $1.2 \times 10^{4} \mathrm{~g} \mathrm{~mol}^{-1}$, if the copolymer is a complete ABA type. Figure 6 gives the relationship between $M_{n}$ and $\eta_{\text {red }}$ for the PA6 homopolymer expressed by,

$$
\eta_{\text {red }}=3.08 \times 10^{-4} \cdot M_{n}^{0.87}
$$

between $M_{n}=4000$ and 30000 . $\eta_{\text {red }}$ for the copolymer (0.56; CP5) was much smaller than that (1.09) calculated by eq 3 when $M_{n}$ was $1.2 \times 10^{4}$. This is because PA6block-PCHMI contains ABA and AB.

\section{Thermal Properties of PA6-block-PCHMI}

The thermal properties of PA6-block-PCHMI prepared from PCHMI having different $T_{\mathrm{g}}$ are summarized in Table III. $T_{\mathrm{m}}$ of PA6 slightly decreased with PCHMI content. $T_{\mathrm{g}}$ of copolymers measured by DSC increased with the weight fraction of PCHMI and did not depend on $T_{\mathrm{g}}$ of the original PCHMI, as shown in Figure 7. The relationship between the $T_{\mathrm{g}}$ and composition of co-

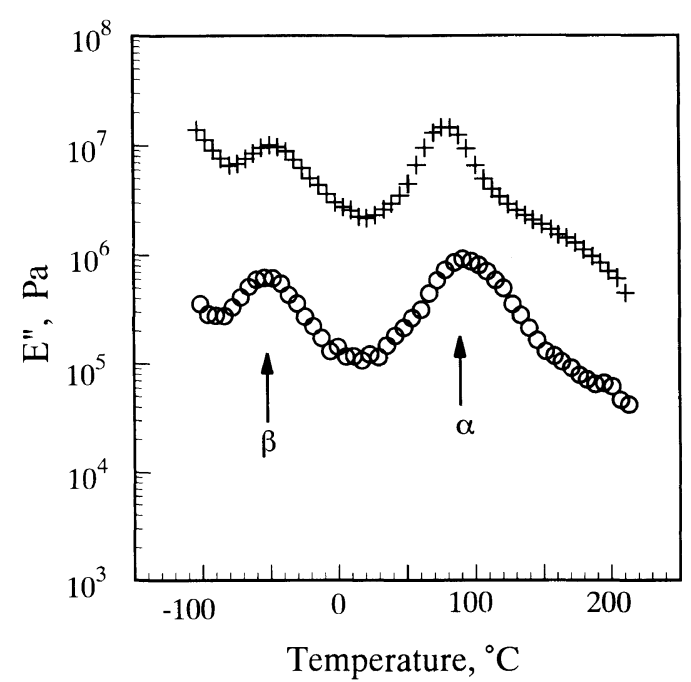

Figure 8. Relationship between loss modulus $E^{\prime \prime}$ and temperature of PA6-block-PCHMI: Run CP18 $(\bigcirc)$ and PA6 homopolymer $(+)$. Run CP $18(\bigcirc)$ : shifted vertically $(\times 0.1)$ for clarity.

polymer is generally expressed by the Fox equation, ${ }^{27}$

$$
\frac{1}{T_{\mathrm{g}}}=\frac{W_{1}}{T_{\mathrm{g} 1}}+\frac{W_{2}}{T_{\mathrm{g} 2}}
$$

where $W_{x}$ is the weight fraction of $x$ component. Change in $T_{\mathrm{g}}$ depending on $M_{n}$ is attributed to the ends of the polymer chains having more free volume than the same number of atoms in the middle of the chain. ${ }^{28}$ Since the end groups, $\mathrm{COOH}$, in the original PCHMI little exist in the copolymer, $T_{\mathrm{g}} \mathrm{s}$ of copolymers were calculated by eq 4 , using $313^{\circ} \mathrm{C}\left(T_{\mathrm{g} \infty}\right.$ of eq 1$)$ as $T_{\mathrm{g}}$ of PCHMI and $42^{\circ} \mathrm{C}$ as that of PA6. The experimental results were consistent with the solid line calculated by eq 4 , as shown in Figure 7.

Figure 8 shows the relationship between loss modulus $E^{\prime \prime}$ and temperature for PA6-block-PCHMI and PA6 homopolymer. The alpha transition $\left(T_{\mathrm{gRSA}}\right)$ of the copolymer became higher than that of PA6, as shown in Table III. Only one $T_{\mathrm{g}}$ of the block copolymer was obtained by DSC and dynamic mechanical measurements. PA6 and PCHMI segments in the PA6-blockPCHMI would thus appear to form a homogeneous phase. 


\section{CONCLUSIONS}

1. Carboxyl group-terminated PCHMIs were obtained by the radical polymerization of CHMI with ACPA as initiator under several conditions. The number of carboxyl groups per polymer chain was smaller than 2.0 .

2. PCHMI had different $T_{\mathrm{g}}$, depending on the molecular weight. $M_{n}$ dependence on $T_{\mathrm{g}}$ could be expressed by the description of Fox and Flory; $T_{\mathrm{g} \infty}$ and $K$ were $313^{\circ} \mathrm{C}$ and $1.26 \times 10^{5}$, respectively.

3. Block copolymers consisting of PA6 and PCHMI were prepared by melt-polymerization of $\mathrm{CL}, \mathrm{ACA}$, and PCHMI. $\eta_{\text {red }}$ of the copolymer became approximately constant after $4 \mathrm{~h}$ polymerization. The copolymers consisted of $\mathrm{ABA}$ and $\mathrm{AB}$.

4. $T_{\mathrm{g}} \mathrm{s}$ of the copolymers were independent of $T_{\mathrm{g}}$ of the original PCHMI, and increased with PCHMI content in the copolymer. The relationship between the $T_{\mathrm{g}}$ and composition could be expressed by the Fox equation.

\section{REFERENCES}

1. J. Stehlíček, J. Horský, J. Roda, and A. Moucha, in "Lactam-Based Polyamides," Vol. 2, R. Puffr and V. Kubánek, Ed., CRC Press, Inc., Boca Raton, FL, 1991, p 20.

2. M. Sano, N. Yui, K. Sanui, N. Ogata, K. Kataoka, T. Okano, and Y. Sakurai, Kobunshi Ronbunshu, 42, 655 (1985).

3. N. Ogata and N. Yui, J. Macromol. Sci. Chem., A21, 1097 (1984).

4. S. Katayama, H. Serita, and Y. Takahashi, J. Polym. Sci., Polym. Chem. Ed., 15, 2109 (1977).

5. J. Stehlíček and J. Šebenda, Eur. Polym. J., 13, 949 (1977).

6. W. L. Hergenrother and R. J. Ambrose, J. Polym. Sci, Polym.
Chem. Ed., 12, 2613 (1974)

7. Y. Shimura and N. Ikeda, J. Polym. Sci., Polym. Chem. Ed., 11, 1271 (1973).

8. M. V. Pandya, M. Subramaniyam, and M. R. Desai, Eur. Polym. J., 33, 789 (1997)

9. M.-S. Yn and C.-C. M. Ma, J. Appl. Polym. Sci., 53, 213 (1994).

10. J. Stehlíček, F. Lednický, J. Baldrian, J. Šebenda, and E. Neuhäusl, Polym. Eng. Sci., 31, 422 (1991).

11. V. Maroušek, P. Svoboda, and J. Králíček, Angew. Makromol. Chem., 178, 85 (1990).

12. W. T. Allen and D. E. Eaves, Angew. Makromol. Chem., 58/59, 321 (1977).

13. I. Cho and K.-W. Lee, Taehan Hwahak Hoechi, 20, 424 (1976); Chem . Abstr., 86, 73165t (1977).

14. V. Nováková, R. Sobotík, J. Matěnová, and J. Roda, Angew. Makromol. Chem., 237, 123 (1996).

15. K. A. H. Lindberg and H. E. Bertilsson, J. Mater. Sci., 26, 4383 (1991).

16. D. Petit, R. Jerome and Ph. Teyssie, J. Polym. Sci., Polym. Chem. Ed., 17, 2903 (1979).

17. R. H. Wondraczek and J. P. Kennedy, J. Polym. Sci., Polym. Chem. Ed., 20, 173 (1982).

18. T. Oishi, Koubunshi Kakou, 41, 314 (1992).

19. T. Oishi and T. Kimura, Koubonshi Ronbunshu, 33, 685 (1976).

20. M. Urushizaki, H. Aida, and H. Ukai, Fukuidaigaku Kougakubu Kenkyuhoukoku, 30, 97 (1982).

21. T. Oishi, H. Yamasaki, and M. Fujimoto, Polym. J., 23, 795 (1991)

22. T. Otsu, M. Yoshioka, and T. Tanaka, Eur. Polym. J., 28, 1325 (1992).

23. T. G. Fox, Jr. and P. J. Flory, J. Appl. Phys., 21, 581 (1950)

24. H. Yumoto and N. Ogata, Makromol. Chem., 35, 71 (1957).

25. Ch. A. Kruissink, G. M. van der Want, and A. J. Staverman, J. Polym. Sci., 30, 67 (1958).

26. M. Hallden-Abberton, Polym. Mater. Sci. Eng., 68, 245 (1993)

27. T. G. Fox, Bull. Am. Phys. Soc., 1, 123 (1952).

28. L. E. Nielsen, in "Mechanical Properties of Polymers and Composites," Vol. 1, Marcel Dekker, Inc., New York, N.Y., 1974, p 22. 